RESEARCH PAPER RP965
Part of Journal of Research of the National Bureau of Standards, Volume 18, January 1937

\title{
PRESSURE LOSSES FOR FLUID FLOW IN CURVED PIPES
}

\author{
By Garbis H. Keulegan and K. Hilding Beij
}

\section{ABSTRACT}

This paper presents the results of a study of the flow of water in smooth-walled, large-radius curved pipes for the viscous and turbulent regimes over a range of Reynolds numbers from 500 to 60,000 . The discussion is based on data obtained with $3 / 8$-inch brass tubing. Two series of tests were made. In the first series pressure losses were measured on ten bends, and simultaneous measurements were made on the downstream tangents. In the second series pressure losses were measured on four equal segments on each of four bends.

The greater part of the paper is devoted to a consideration of the results in the viscous flow regime. In this part of the investigation care was taken to assure parabolic velocity distribution, or nearly so, at the entrance of the bends. Empirical formulas are given for the effective resistance coefficient of an entire bend and for the downstream tangent. A method of computing to a first approximation the length of curve required for the establishment of the velocity distribution characteristic of a curved pipe is presented.

Critical numbers for bends of different curvature ratios when the entering flow is laminar are briefly discussed. Average values for the relative increase in resistance in a bend as compared with straight pipe in the regime of turbulent flow are given for the range of Reynolds numbers from 40,000 to 60,000.

CONTENTS

Page

I. Introduction

1. Previous work

2. Scope of present investigation

II. Apparatus _. 93

III. Experimental pipes_.

IV. Experimental results for viscous flow

1. Resistance in bends, including transition segment_...... 97

2. The transition segment of a bend. 102

3. Resistance in a straight pipe below a bend

V. Transition from viscous to turbulent flow

VI. Experimental results for turbulent flow

\section{INTRODUCTION}

A curved pipe or pipe bend, in the restricted sense used in this paper, is a pipe of circular cross section bent to the form of a circular arc. The straight pipes that connect to the two ends of the bend always lie in the plane of the bend, as is implied by the terms, upstream tangent and downstream tangent, used in this paper.

When a fluid flows under pressure through a straight horizontal pipe, the pressure decreases in the direction of flow as a consequence of the energy loss resulting from fluid friction. A thin layer of the fluid adheres to the wall of the pipe and remains at rest with respect to it. Thus the velocity of the fluid at any cross section increases from zero at the wall to a maximum at the axis of the straight pipe. If fully 
developed laminar ${ }^{1}$ flow exists, the curve obtained by plotting velocity against distance from the pipe axis (called the velocity distribution curve or the velocity profile) is a parabola, and the loss of energy is brought about by the viscous resistance to sliding of concentric layers of the fluid over each other. If the flow is turbulent, the loss of energy is greater and is due mainly to turbulent mixing of the fluid. In this case the velocity profile is flatter near the axis of the pipe and steeper near the wall than it is for laminar flow.

Now if the pipe is curved instead of straight, the velocity profile will no longer be symmetrical about the axis of the pipe. Centrifugal force due to the change in direction of the flow sets up secondary currents in the plane of the cross section, with the result that the maximum velocity is no longer at the center of the section but at some point intermediate between the center and the wall. It is found, as might be expected, that this distortion of the velocity profile is accompanied by larger pressure losses along the pipe than occur for the same flow with the symmetrical profile that is characteristic of a straight pipe. Hence a curved pipe always offers more resistance to the flow of a fluid than would the same pipe if straight. At very small Reynolds numbers, however, the difference is so slight, that it cannot be measured by the methods ordinarily employed.

In the present experiments, the water was brought into the upstream tangent through a bell-shaped entrance. As is well known, such an entrance tends to produce uniform velocity distribution over the cross section at its exit. However, as the water flows along the straight pipe comprising the upstream tangent, this flat velocity profile changes, gradually assuming the form that is characteristic of the straight pipe, until a point is reached, if the pipe is long enough, beyond which this characteristic profile persists unchanged throughout the remainder of the length of the straight pipe. The portion of the pipe in which the velocity profile changes from one definite form to another form, characteristic of the pipe in question, is called the transition segment, and the length of this segment is called the transition length.

Since the velocity profile that exists at the entrance to the bend is not the characteristic form for the curved pipe, however, another readjustment takes place in the bend, and if the latter is long enough, a new velocity profile that is characteristic of the curved pipe and the existing flow conditions will become established some distance downstream from the entrance to the bend, and will persist unchanged to the downstream end of the bend. The terms transition segment and transition length are applicable to the bend as well as to the straight pipe. It was also found convenient to distinguish between long bends-those which are longer than the transition length, and short bends-those which are shorter than the transition length.

Another readjustment of the velocity profile takes place in the downstream tangent just below the bend, since the profile characteristic of the bend must now change back to that characteristic of the straight pipe.

It is evident, therefore, that we cannot confine our attention to the bend alone in considering the total loss of pressure caused by a bend, for the pressure loss in the transition segment of the bend depends on the particular velocity profile at the bend entrance, and this is deter-

\footnotetext{
1 Throughout this paper the term viscous flow will be used to designate flow at Reynolds numbers below the critical. While viscous flow is laminar in straight pipes, it is not so in curved pipes, because of the secondary currents which result from the curvature.
} 
mined by the conditions in the upstream tangent. Also the pressure loss in the transition section of the downstream tangent will be greater than that in an equal length of straight pipe in which fully developed laminar velocity distribution prevails. This excess pressure loss that occurs in the transition segment of the downstream tangent is due to the readjustment of the velocity distribution that takes place here.

The loss of pressure in any pipe, straight or curved, is given by the relation

where

$$
\frac{1}{\gamma} \frac{\Delta p}{\Delta x}=\lambda \cdot \frac{l}{d} \cdot \frac{U^{2}}{2 g}
$$

$\gamma=$ the specific weight of the fluid,

$\Delta p=$ the pressure drop at the axis of the pipe over an axial length $\Delta x$,

$\lambda=$ the coefficient of resistance,

$d=$ the pipe diameter,

$U=$ the mean of the velocity components parallel to the axis in a cross section, and

$g=$ the acceleration of gravity.

When the velocity distribution is the same for all cross sections, as in straight pipes or bends downstream from the adjustment length, the pressure drop, $\Delta p$, is the same for all elementary lengths, $\Delta x$, and the coefficient of resistance is constant along the pipe for any given flow. Under these conditions, for a smooth straight pipe, the resistance coefficient is a function of the Reynolds number only, the Reynolds number being defined by

$$
R_{e} \equiv \frac{d U}{\nu},
$$

where $\nu$ is the kinematic viscosity of the fluid. For laminar flow we have

$$
\lambda=64 / R_{e},
$$

and for turbulent flow, below a Reynolds number of about 130,000, the empirical relation

$$
\lambda=C R_{e}^{-1 / 4},
$$

where $C$, as experimentally determined, has a value in the neighborhood of 0.31 .

When the velocity distribution varies from section to section, as in any transition segment, the pressure drop also varies, and hence the coefficient of resistance at any given flow is different for all elementary lengths, $\Delta x$.

As the coefficient of resistance is determined experimentally by the application of equation 1, it is necessary to measure the pressure in the axis of the pipe at any two given cross sections in order to determine the pressure drop $\Delta p$. If the directions of the absolute velocities at all points in a cross section are parallel to the pipe axis, then the pressure is constant over the entire cross section. It may, therefore, be measured at any point in the section and, in particular, at the wall of the pipe.

In a curved pipe, because of the curvilinear paths of the moving fluid particles, the pressures, $p_{i}$ and $p_{o}$, at the inner and outer ends, respectively, of a diameter in the plane of the curve are not equal. At the ends of a diameter normal to the plane of the bend of the pres- 
sures, $p_{n}$, are equal on account of symmetry. However, if the radius of curvature of the bend is large compared with the pipe diameter, then

$$
p_{i}+p_{o}=2 p_{n},
$$

a fact which was verified by Richter ${ }^{2}$ for turbulent flow. Undoubtedly it applies to viscous flow also. It is generally assumed by experimenters that when equation 4 holds, the mean pressure in a cross section is given by $\left(p_{i}+p_{o}\right) / 2$, or by $p_{n}$, and this mean pressure may be taken as the axial pressure, with negligible error. Accordingly, in this investigation pressures were measured either by averaging the pressures at the two ends of the diameter normal to the plane of the bend, or by averaging these two and also those at the ends of the diameter in the plane of the bend.

\section{PREVIOUS WORK}

There are very few reported investigations, either theoretical or experimental, on flow in long pipe bends. The theoretical treatment for viscous flow is complicated so greatly by the existence of secondary currents arising from the centrifugal action of the curvilinear flow that no general rigorous solution has been obtained. The first attempt at a theory was made by Dean. ${ }^{3}$ Although he made but little progress toward the derivation of a theoretical expression for flow in bends, his analysis proved to be very valuable in subsequent work for two reasons. A first result of his analysis related to the law of similarity for mean velocities in curved pipes. His original mathematical statement of the law can be simplified if we introduce the shear velocity in place of the pressure gradient. The law can then be stated as follows: for a given shear the ratio of the mean velocities in two pipes of the same dimensions, one straight and the other curved, depends on a parameter given by the product

where

$$
\left(\frac{U_{*} d}{\nu}\right)^{2}\left(\frac{d}{D}\right)^{1 / 2}
$$

$$
\begin{aligned}
T_{*} & =(\tau / \rho)^{1 / 2} \text { is the shear velocity, } \\
\tau & =\text { the mean shear at the wall, } \\
\rho & =\text { the density of the fluid, } \\
d & =\text { the diameter of the pipe, } \\
D & =\text { twice the radius of the bend, and } \\
\nu & =\text { the kinematic viscosity of the fluid. }
\end{aligned}
$$

(It is convenient to call the ratio $d / D$ the curvature ratio of the bend.) However, White ${ }^{4}$ found it more convenient to apply the converse of the above law. The converse law can be stated: for a given mean velocity in two pipes of the same dimensions, one straight and the other curved, the ratio of the resistances depends on a parameter given by the product of the Reynolds number and the square root of the curvature ratio; that is, $R_{e} .(d / D)^{1 / 2}$. With this as a starting point White was able to correlate the results of his experiments. The relative increase of resistance due to curvature was found to be a

\footnotetext{
${ }^{2}$ H. Richter, Der Druckabfall in glatten gekrümmten Rohrleitungen. Ver. deut. Ing. Forsch. Heft 338 (1930).

${ }^{3}$ W. R. Dean, The streamline motion of fluid in a curved pipe. Phil. Mag. [7] 4, 208 (1927); 5, 673 (1928).

C. M. White, Streamline flow through curved pipes. Proc. Roy. Soc. (London) 123, [A] 645 (1929).
} 
function of $R_{e} \cdot(d / D)^{1 / 2}$ provided the flow in the bends did not become turbulent.

The second result of Dean's analysis was an explanation of the manner in which two symmetrical circulations or secondary currents are set up in a bend. Taylor's ${ }^{5}$ study of the onset of turbulence in curved pipes was based on the existence of these secondary currents. The introduction of dyes through perforations at the ends of a horizontal diameter of a bend made the secondary currents visible, and the disturbance of these currents formed a satisfactory criterion for the onset of turbulence. Eustice's ${ }^{6}$ method of introducing dyes at the entrance of the bend had previously proved unsuccessful.

Considerable information is given by Adler ${ }^{7}$ on the distribution of axial velocities both for viscous and for turbulent flows. After obtaining experimental data on the nature of the flow in the central core, he gives an interesting derivation of an expression for the resistance coefficient for viscous flow at large values of $R_{e}(d / D)^{1 / 2}$ by making use of the Prandtl boundary layer theory.

\section{SCOPE OF PRESENT INVESTIGATION}

The results of the above-mentioned investigations on resistance coefficients for viscous flow in long bends apply only to segments of bends downstream from the transition segment. The chief purpose of the investigation which forms the subject of this paper was to furnish the data required for calculating the total resistance due to a long bend. It was necessary, therefore, to determine the effective resistance coefficient for the complete bend including the transition segment, and also the effect of the bend on the resistance coefficient of the downstream tangent.

The critical number (the Reynolds number at which viscous flow becomes unstable and changes to turbulent flow) was determined for each bend. Data were obtained for turbulent flow up to the maximum flow possible with the apparatus, which corresponded to a Reynolds number of about 60,000 .

\section{APPARATUS}

The water supply system is shown in figure 1. For low flows (below the critical), the constant level tank was used to supply water under a constant head. For the higher flows, water was drawn directly from the city mains at a pressure of about $30 \mathrm{lb} / \mathrm{in}^{2}$. By the use of the surge tank, the effects of sudden and severe pressure changes in the supply from the city mains were reduced considerably, but they could not be altogether eliminated. To insure minimum disturbance of the flow at the entrance to the experimental pipe, the supply line was increased from a 3 -inch diameter in the vertical portion by means of an expander and an expanding elbow to a diameter of 8 inches in the pipe forming the supply chamber. The entrance cone of the experimental pipe was mounted at the center of a flange on the end of the 8-inch pipe. A valve at the end of the exit pipe was used to control the flow. Below the valve was a pocket for the thermometer and a swinging gooseneck for diverting the flow from the waste line to the measuring tank. The thermometer was gradu-

$\checkmark$ G. I. Taylor, The criterion for turbulence in curved passages. Proc. Roy. Soc. (London) 124, [A] 243 (1929)

6 J. Eustice, Flow of fluids in curved passages. Engineering 120, 604 (1925).

7 M. Adler, Strōmung in gekrümmten Rohren. Z. ang. Math. u. Mech. 14, 257 (1934). 
ated in $0.2^{\circ} \mathrm{C}$, and was read to the nearest $0.1^{\circ} \mathrm{C}$. A volumetric tank, calibrated by weighing, with a float gage connected to a pointer indicating on a dial face, was used for measurement of flow. Times were measured with a stop watch.

Measurements of head were made by means of water manometers for the lower flows and mercury manometers for the higher flows. Capillary tubes were used to damp out the manometer oscillations to the point where they were barely noticeable. Another purpose of the capillary tubes was to preserve the stability of viscous flow in the test line. At Reynolds numbers above 3,000, slight pressure oscillations caused flow into and out of the piezometer openings when capillaries were not used, and the resulting disturbance often was sufficient to bring on turbulence in the test pipes. All manometer readings were made to the nearest $0.1 \mathrm{~mm}$ by means of a cathetometer.

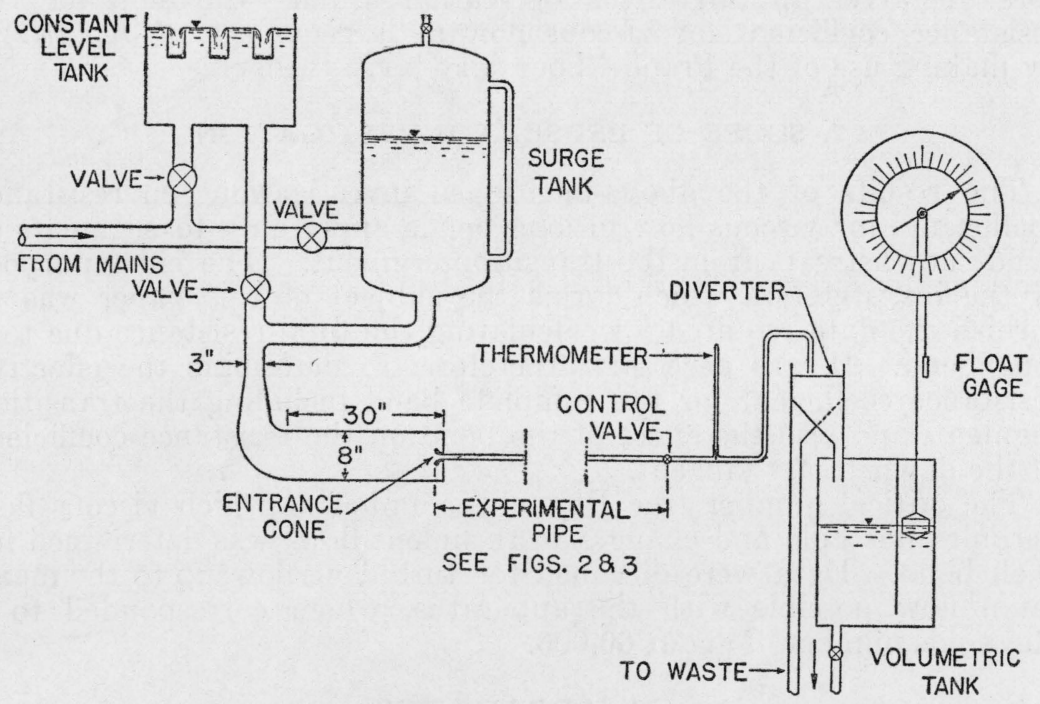

Figure 1.-Arrangement of experimental apparatus.

\section{EXPERIMENTAL PIPES}

All the experimental pipes were of smooth, drawn-brass tubing, of nominal $3 / 8$-inch internal diameter, specially selected for straightness and uniformity of bore. The lengths, measured internal diameters, and arrangement of the pipes are shown in figure 2 .

Effective pipe diameters were determined by weighing the amount of water necessary to fill the pipe completely. Uniformity of cross section was determined by measuring outside diameters by micrometer gages, assuming a uniform wall thickness.

The critical number for a bend increases with increasing curvature ratio, so that above a certain Reynolds number it is possible for turbulent flow to exist in the entrance pipe and the upstream end of the bend, with viscous flow existing in the downstream end of the bend. (See section V.) As it was desired to exclude this condition from the scope of the investigation, special precautions were necessary in the design of the entrance pipe. Now, the critical number for a bend of 
the largest curvature ratio to be tested was known from the work of other experimenters to be in the neighborhood of 5,000 (see fig. 12), so that an entrance pipe was required having a critical number of at least 6,000 . This condition was realized by using the bell-shaped entrance cone shown in figure 3 , connected to a long entrance segment of straight pipe, shown in figure 2 .

Two series of tests were made. In the first series, resistance coefficients for two pipes, no. 1 and 2 in figure 2, were measured. All the bends were formed from pipe no. 1, which, for each test, was bent elastically into a circular arc of the curvature ratio desired. Pipe no.

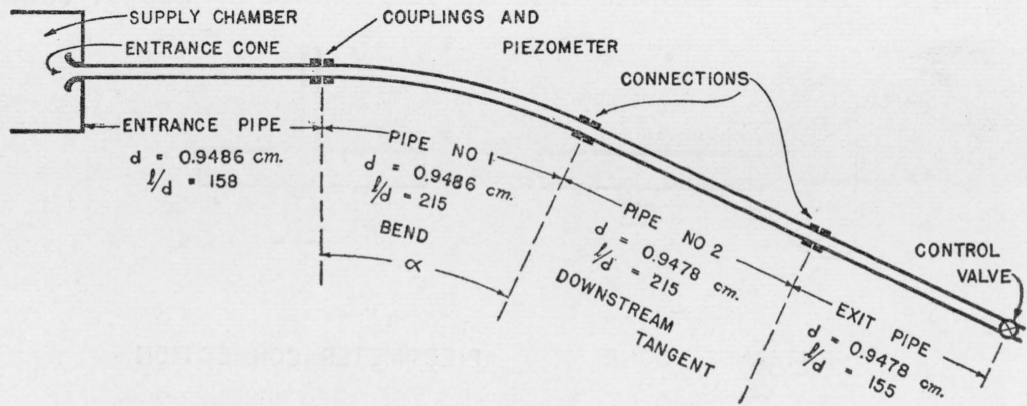

ARRANGEMENT FOR SERIES I TESTS

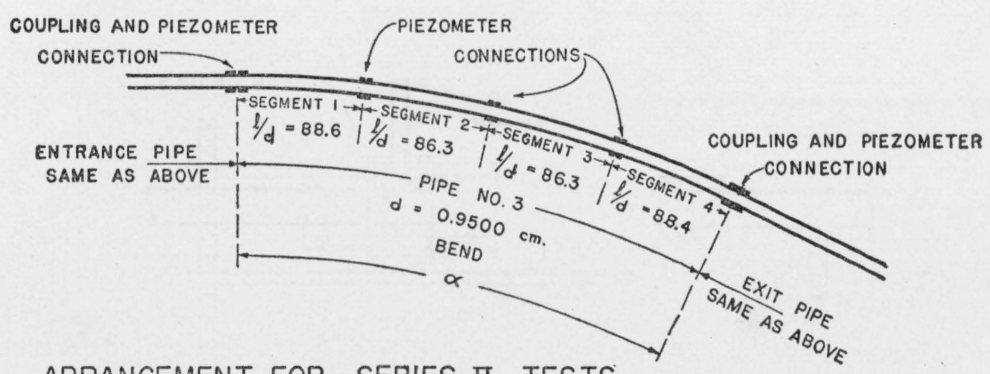

ARRANGEMENT FOR SERIES II TESTS

FIgURe 2.-Experimental pipes with pipe dimensions.

2 was always kept straight and connected to the downstream end of the bend. In the second series, resistance coefficients were determined for four approximately equal segments of pipe no. 3 (fig. 2) which was bent elastically to form the bends.

In order to determine the deformations of the pipes caused by bending, the following procedure was used. A pipe of the same material and dimensions as those used in the tests was closed at one end and this end clamped to a table. At the fixed end was attached a vertical glass tube of $0.5-\mathrm{mm}$ bore. The pipe was then completely filled with water and the free end closed. Next the pipe was bent into horizontal arcs of various curvatures and the corresponding rise of water in the glass capillary was determined. The relative decrease of internal volume $(\Delta V / V)$ due to bending appeared to vary as the square of the curvature: for $d / D=69.7 \times 10^{-4}, \Delta V / V=7.8 \times 10^{-4}$. The external diameters at the midpoint of the pipe were also meas$110639-37-7$ 
ured for this curvature. The vertical diameter increased by $0.004 d$; while the horizontal diameter (in the plane of the arc) decreased by $0.006 d$. These measurements indicate a decrease in effective diameter of about 1 part in 1,000. It was assumed that these changes of form were sufficiently small so that no correction was required for deformation of the pipes.

The experimental pipes were connected by special couplings, the details of which are shown in figure 3 . With this arrangement, every joint could be inspected easily. In each coupling were four piezometer openings $1 \mathrm{~mm}$ in diameter, connecting to a piezometer ring. This ring was connected to the manometer by copper tubing.

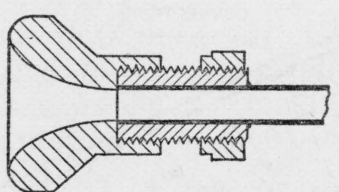

ENTRANCE CONE

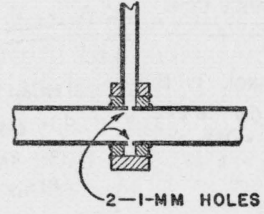

PIEZOMETER CONNECTION
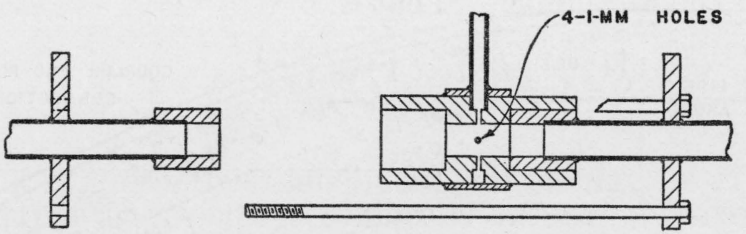

\section{COUPLING AND PIEZOMETER CONNECTION}

FIGURE 3.-Fittings for experimental pipes.

In addition to the couplings at the ends, pipe no. 3 was provided with three sets of piezometer openings as shown in figure 2. Each set consisted of two 1-mm holes on the vertical diameter connected to a piezometer ring.

\section{EXPERIMENTAL RESULTS FOR VISCOUS FLOW}

The results of the series $I$ tests on the bends formed from pipe no. 1 are given in figures $5,6,13,14$, and 15 , and on the downstream tangent, pipe no. 2 , in figures $9,10,13,14$, and 15 . The results of the series $I I$ tests on the bends formed from pipe no. 3 are given in figures 4 and 7 . In each figure the data are presented in a manner conforming to the analysis of the results in the following discussions. 


\section{RESISTANCE IN BENDS, INCLUDING TRANSITION SEGMENT}

The following discussion applies to viscous flow with parabolic or nearly parabolic velocity distribution at the entrance of the bend. The resistance coefficient at the entrance, therefore, is the same as that for a straight pipe. Denote this coefficient by $\lambda_{s}$.

At a certain axial distance $x_{1}$, measured from the entrance to the bend, the velocity distribution assumes a pattern which is characteristic of the bend, and which persists from this point to the end of the bend. The distance $x_{1}$ is thus the transition length, and the corresponding portion of the bend is the transition segment. Downstream from the transition segment the coefficient of resistance will be constant and will be denoted by $\lambda_{c}$. In the transition segment the coefficient of resistance will increase from its value $\lambda_{s}$ at the entrance to its value $\lambda_{c}$ at $x_{1}$. The effective coefficient $\lambda_{x}$ of any segment of the bend (beginning at the entrance) of length $x$ where $x_{1}<x<l$ will, therefore, vary with $x$. This effective coefficient is defined by the relation

$$
\frac{1}{\gamma} \Delta p=\lambda_{x} \frac{x}{d} \frac{U^{2}}{2 g}
$$

where $\Delta p$ is the pressure loss between the entrance of the bend and the point at distance $x$ downstream, $d$ is the pipe diameter, $U$ is the mean velocity, and $g$ is the acceleration of gravity. In general, we should anticipate that $\lambda_{x}$ will be a function of $x / d$, the relative length of the bend segment, as well as of $d / D$, the curvature ratio of the bend, and $R_{e}$, the Reynolds number. That is:

$$
\lambda_{x}=\text { funct. }\left(\frac{x}{d}, \frac{d}{D}, R_{e}\right) \text {. }
$$

The problem is to evaluate this functional relationship.

Evidently, considering the resistance coefficient as a function of the bend length, we may write

$$
\lambda_{x} \cdot x=\int_{0}^{x_{1}} \lambda_{a} d x+\lambda_{c}\left(x-x_{1}\right)
$$

where $\lambda_{a}$ is the resistance coefficient for an infinitesimal length $d x$ of the bend at any point $x=a$ in the transition segment, i. e., $0<a<x_{1}$. Hence $\lambda_{a}$ is a local coefficient applying only to the point $a$, while $\lambda_{x}$, the effective resistance coefficient, is an average value for a length $x$ of bend, where $x>x_{1}$, and $\lambda_{c}$ is constant for the bend segment between the points $x_{1}$ and $x$. Since the terminal values of $\lambda_{a}$ are $\lambda_{s}$ at $x=0$, and $\lambda_{c}$ at $x=x_{1}$, the integral in equation 7 may be replaced by

$$
\int_{0}^{x_{1}} \lambda_{a} d x=k_{x}\left(\lambda_{c}-\lambda_{s}\right) x_{1}+\lambda_{s} x_{1}
$$

From equations 7 and 8 ,

$$
\lambda_{x} \cdot x=k_{x}\left(\lambda_{c}-\lambda_{s}\right) x_{1}+\lambda_{s} x_{1}+\lambda_{c}\left(x-x_{1}\right),
$$


which on rearrangement and division by $d$ becomes

$$
\frac{\lambda_{c}-\lambda_{x}}{\lambda_{c}-\lambda_{s}} \cdot \frac{x}{d}=\left(1-k_{x}\right) \frac{x_{1}}{d}
$$

Writing for convenience,

$$
\left(1-k_{x}\right) \frac{x_{1}}{d} \equiv \beta,
$$

and dividing the numerator and denominator of the left-hand member of equation 9 by $\lambda_{s}$, we have

$$
\frac{\frac{\lambda_{c}}{\lambda_{s}}-\frac{\lambda_{x}}{\lambda_{s}}}{\frac{\lambda_{c}}{\lambda_{s}}-1} \cdot \frac{x}{d}=\beta .
$$

The two unknown quantities, $k_{x}$ and $x_{1}$, are thus combined in the single unknown quantity $\beta$. In order to determine from equation 11 the dimensionless quantity $\beta$ as a function of the Reynolds number $R_{e}$ and the curvature ratio $d / D$ it is necessary to find the values of the three resistance coefficients:

$$
\lambda_{s}, \lambda_{c} \text {, and } \lambda_{x} .
$$

The value of $\lambda_{s}$, when the velocity distribution is parabolic, follows from Poiseulle's law and, as previously stated, is given by

$$
\lambda_{s}=64 / R_{e} .
$$

The results of the initial experiment of the series $I$ tests, for which pipe no. 1 was kept straight, agreed within small experimental errors with the relation (equation 2) up to a Reynolds number of about 4,500. At higher Reynolds numbers the experimentally determined values of $\lambda_{s}$ became progressively greater than those given by equation 2 , as shown in the upper left-hand graph in figure 13. Taking a Reynolds number of 7,000 for the purpose of comparison, we find that $\lambda_{s}$ by equation 2 is equal to 0.00914 , while the observed value for pipe no. 1 is 0.0102 .

According to Schiller's method of computation ${ }^{8}$ for the transition segment of a straight pipe, the effective coefficient for pipe no. 1 at a Reynolds number of 7,000 should be 0.00924 . The difference between this result and the experimental value is far too large to be accounted for by experimental errors, so that only a small part of the discrepancy can be attributed to the fact that the entrance pipe was too short at the higher Reynolds numbers.

In his original paper Schiller ${ }^{9}$ states that a very slight deviation from absolute straightness of his experimental pipe produced considerable changes in resistance. This clue affords a possible explanation of the high values of $\lambda$ experimentally determined.

${ }^{8}$ See p. 25, et seq., in Prandtl-Tietjens, Applied Hydro- and Aero-Mechanics, (McGraw-Hill Book Co., New York, N. Y., 1934).

9 L. Schiller, Untersuchungen über laminare und turbulente Strömung, Ver. deut. Ing. Forsch. Heft 248 (19.2). 
From the graph in figure 4 we can compute approximately the curvature of pipe no. 1 necessary to give a value of $\lambda=0.0102$ at a Reynolds number of 7,000. We have

$$
\frac{\lambda}{\lambda_{s}}=\frac{0.0102}{0.00914}=1.12,
$$

and hence, by figure 4 ,

$$
R_{e}\left(\frac{d}{D}\right)^{1 / 2}=30, \text { approximately. }
$$

As $R_{e}=7,000$, and $d=0.95$, we find

$$
D=55,000 \mathrm{~cm} .
$$

If pipe no. 1 were bent to an are of this diameter, the distance between the arc and the chord at the center-point of the arc would be about $2 \mathrm{~mm}$. There was no sag in the pipe, since it was continuously supported, and in the horizontal plane there certainly was no deviation of more than $0.5 \mathrm{~mm}$ from a straight line. But if the pipe were sinuous, say forming two ares of $55,000 \mathrm{~cm}$ diameter, then the maximum deviation from a straight line would be only about $0.5 \mathrm{~mm}$. It is quite possible, therefore, that an apparently insignificant residual curvature in the pipe was sufficient to account for the high resistance coefficients observed.

As any such residual curvature would be inappreciable in comparison with the relatively large curvature imposed on pipe no. 1 when the bends were formed, the value of $\lambda_{s}$ from equation 2 , that is, for $\mathbf{a}$ truly straight pipe, is the proper one to use in equation 11.

White and Adler (see footnotes 4 and 7) have determined $\lambda_{c}$ as a function of Dean's parameter, $R_{e}(d / D)^{1 / 2}$. However, it was decided to make a new determination of $\lambda_{c}$ (see fig. 4), in order that all data of this investigation might be derived from the same source and might, therefore, be on a strictly comparable basis. The series $I I$ tests were made for this purpose, the experimental layout being that shown in figure 2.

An examination of the data showed that the resistance coefficients of the two segments furthest downstream (segments 3 and 4) were the same for all of the tests and larger than the corresponding coefficients for segment 1 . The coefficients for the segment 2 were slightly smaller than those for the two downstream segments in some of the tests. It was judged that the two downstream segments were not appreciably affected by entrance effects. Accordingly, the resistance coefficient for the downstream half of the bend (segments 3 and 4) was taken as the value of $\lambda_{c}$ and was computed from an equation similar to equation 1. The results are given in figure 4 , where the ratio $\lambda_{c} / \lambda_{s}$ is plotted as a function of $R_{e} \cdot(d / D)^{1 / 2}$. These values are from 1 to 2 percent lower than those of White (see footnote 4).

From the same series of tests, values of $\lambda_{x}$ were determined for two segment lengths, segment 1 alone and segments 1 and 2 combined, that is for values of $x / d$ equal to 88.6 and 174.9 , respectively. From the first series of tests values of $\lambda_{x}$ were determined for 10 different curvatures, all of the same segment length, $x / d=215$. The resuits of 
these two series of tests are given in figures 5,6 , and 7 , in which the ratios $\lambda_{x} / \lambda_{s}$ are plotted as a function of the Reynolds number.

The data in figures 4 to 7 may now be used to compute $\beta$ by means of equation 11. If $\beta$ is independent of the Reynolds number, then it should be possible to fit a curve corresponding to a constant value of $\beta$ to each of the sets of points in figures 5, 6, and 7. Accordingly, a tentative curve was drawn through each set of test points, and values of $\lambda_{x} / \lambda_{s}$ were read from each curve for about a dozen Reynolds numbers. The corresponding values of $\lambda_{c} / \lambda_{s}$ were obtained from the curve in figure 4. Then values of $\beta$ were computed, using equation 11. A second approximation (in some few cases a third) by shifting slightly

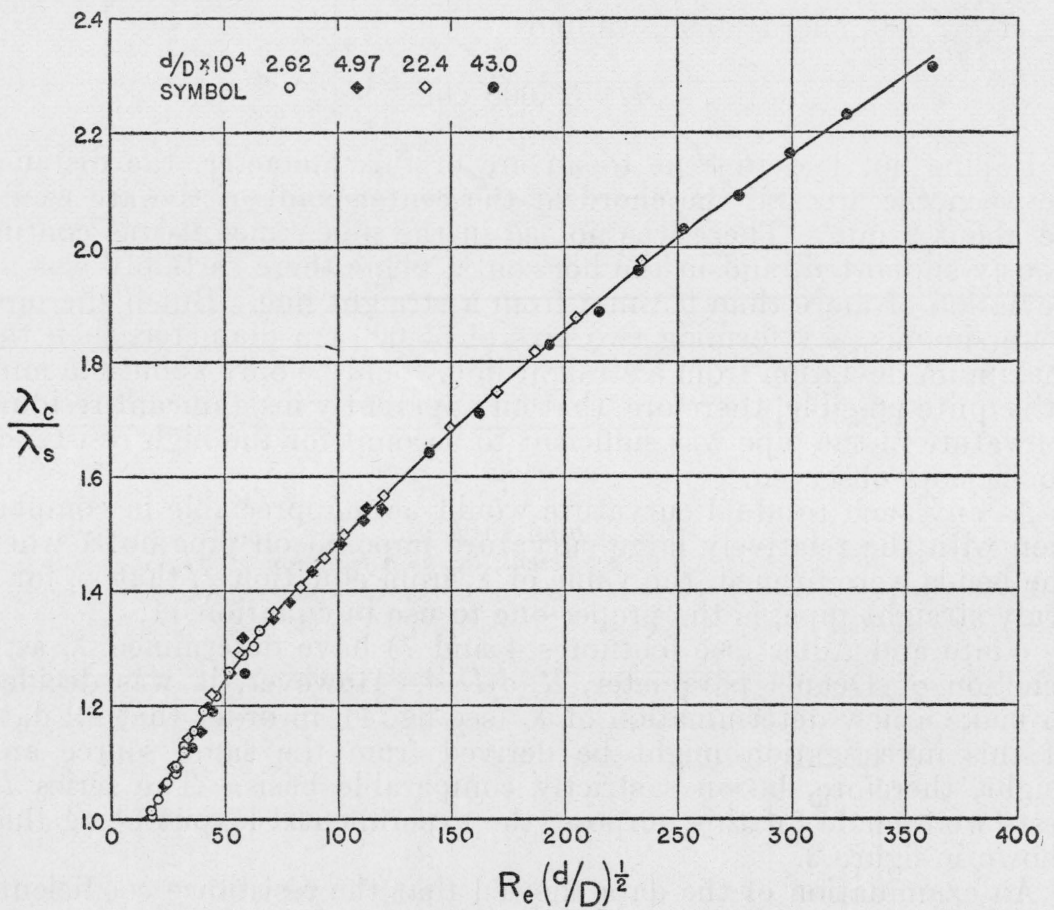

FIgURe 4.-Ratio of the bend coefficient, $\lambda_{c}$, to the straight pipe coefficient, $\lambda_{s}$, as a function of $R_{e}(d / D)^{1 / 2}$.

the tentative curves, sufficed to give practically constant values of $\beta$ for each set of test points, i. e., for each bend. The final values adopted for $\beta$ are given in table 1 , and the corresponding curves are drawn in figures 5,6 , and 7 . These curves appear to fit the data better than did the original tentative curves. The satisfactory agreement of the curves with the experimental points shows that $\beta$ may be regarded as independent of the Reynolds number, within the limits of experimental error. 


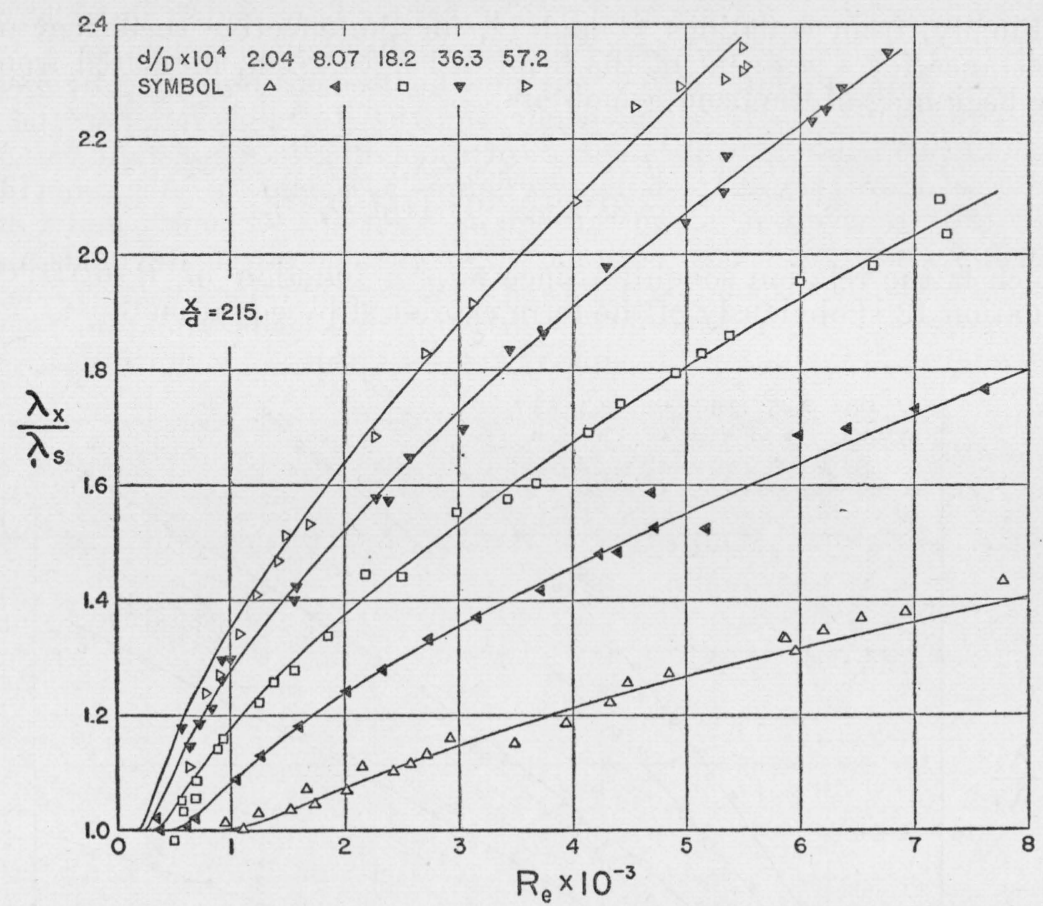

Figure 5.-Ratio of the effective bend coefficient, $\lambda_{x}$, for bends of relative length $x / d=215$, to the straight pipe coefficient, $\lambda_{s}$, as a function of Reynolds number.

The points represent experimental values and each curve represents a constant value of $\beta$ as given in table 1. See also figures 6 and 7 .

TABLE 1.-Relation between $\beta$ and the curvature ratio $d / D$

\begin{tabular}{|c|c|c|c|c|c|}
\hline$d$ & $x / d$ & $d / D \times 10^{4}$ & $(d / D)^{1 / 2} \times 10^{2}$ & $\beta$ & $1 / \beta$ \\
\hline 0.949 & 215.0 & $\begin{array}{c}2.04 \\
4.45 \\
8.07 \\
12.8 \\
18.2 \\
24.2 \\
36.3 \\
45.3 \\
57.2 \\
69.7\end{array}$ & $\begin{array}{l}1.43 \\
2.12 \\
2.84 \\
3.58 \\
4.27 \\
4.92 \\
6.03 \\
6.73 \\
7.56 \\
8.35\end{array}$ & $\begin{array}{l}54.9 \\
42.7 \\
33.3 \\
26.0 \\
23.3 \\
21.5 \\
17.5 \\
16.2 \\
14.2 \\
13.0\end{array}$ & $\begin{array}{l}0.0182 \\
.0234 \\
.0300 \\
.0384 \\
.0429 \\
.0465 \\
.0570 \\
.0618 \\
.0702 \\
.0768\end{array}$ \\
\hline .950 & 88.6 & $\begin{array}{l}2.62 \\
4.97 \\
22.4 \\
43.0\end{array}$ & $\begin{array}{l}\text { 1. } 62 \\
2.23 \\
4.73 \\
6.56\end{array}$ & $\begin{array}{l}50.0 \\
41.3 \\
22.2 \\
16.2\end{array}$ & $\begin{array}{l}.0200 \\
.0242 \\
.0450 \\
.0617\end{array}$ \\
\hline .950 & 174.9 & $\begin{array}{c}2.62 \\
4.97 \\
22.4 \\
43.0\end{array}$ & $\begin{array}{l}\text { 1. } 62 \\
\text { 2. } 23 \\
\text { 4. } 73 \\
\text { 6. } 56\end{array}$ & $\begin{array}{l}54.3 \\
40.5 \\
21.6 \\
16.8\end{array}$ & $\begin{array}{l}.0184 \\
.0247 \\
.0462 \\
.0596\end{array}$ \\
\hline
\end{tabular}

From the results given in table 1, a simple empirical relationship between $\beta$ and the curvature ratio $d / D$ was found by plotting $1 / \beta$ as a function of $(d / D)^{1 / 2}$, as shown in figure 8 . The points in this figure are represented very satisfactorily by the straight line given by the equation

$$
1 / \beta=0.0059+0.844(d / D)^{1 / 2} .
$$


Finally, from equations 11 and 12, for the effective coefficient of resistance for a segment of the bend of length $x>x_{1}$, measured from the beginning of the bend, we obtain

$$
\lambda_{x}=\lambda_{c}-\frac{d}{x} \cdot \frac{\left(\lambda_{c}-\lambda_{s}\right)}{\left(0.0059+0.844(d / D)^{1 / 2}\right)},
$$

which is the relation sought. Since $\lambda_{c}$ is a function of $R_{e} \cdot(d / D)^{1 / 2}$, equation 13 is obviously of the form expressed by equation 6 .

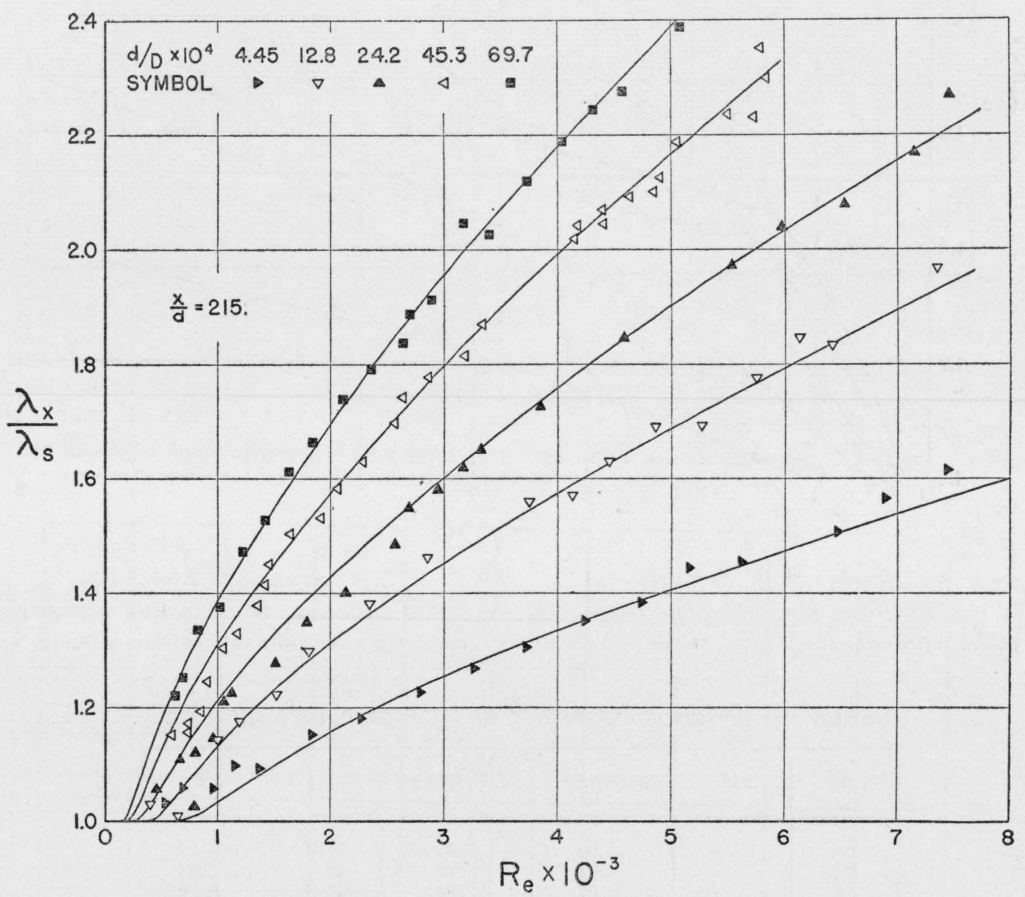

FIGURE 6.-Ratio of the effective bend coefficient, $\lambda_{x}$, for bends of relative length $x / d=215$, to the straight pipe coefficient, $\lambda_{s}$, as a function of Reynolds number.

The points represent experimental values, and each curve represents a constant value of $\beta$ as given in table 1. See also figures 5 and 7.

\section{THE TRANSITION SEGMENT OF A BEND}

The length $x_{1}$ of the transition segment of a bend cannot be derived from any experimental data known to the authors. All that is known from this investigation is that $\beta$, and hence $\left(1-k_{x}\right) x_{1}$, is independent of the Reynolds number and is a function of the curvature ratio $d / D$. If $k_{x}$ should prove to be independent of the Reynolds number, then $x_{1}$ would be also. To settle this point effectively, experimental data must be obtained for a series of values of $x<x_{1}$. In order to obtain head losses large enough to be accurately measured, $x_{1}$ must be large. At the same time, $d / D$ must include at least the range of values covered in the present experiments, and hence $x_{1} / d$ must be approximately of the same magnitude as in the present experiments. Therefore, pipes of considerably larger diameter are required. As the 


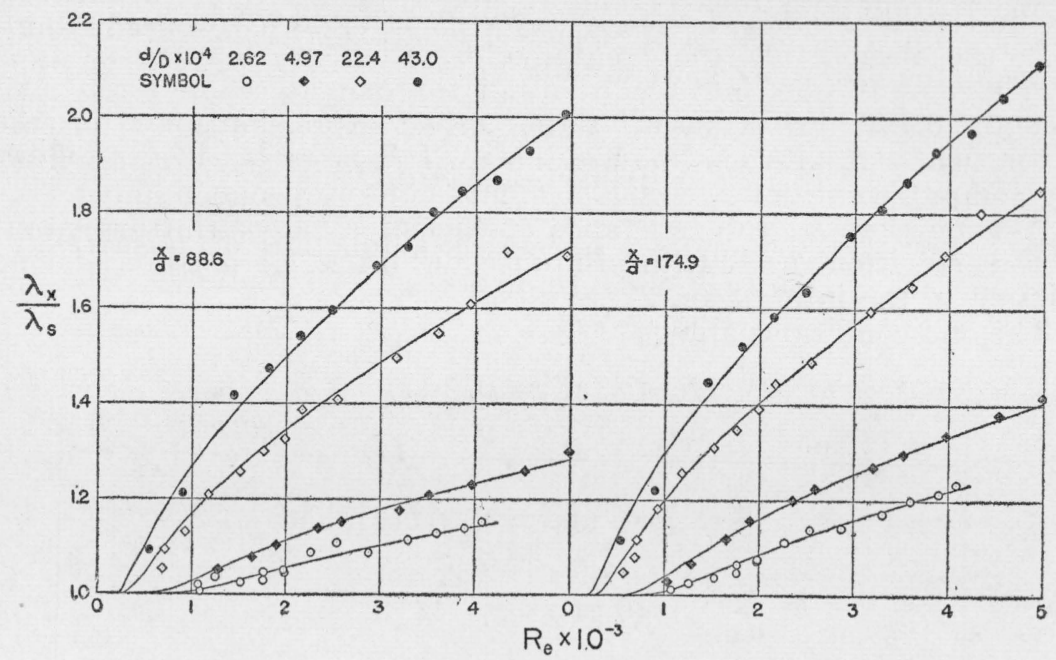

FIGURE 7.-Ratio of the effective bend coefficient, $\lambda_{x}$, for bends of relative lengths $x / d=88.6$ and $x / d=174.9$, to the straight pipe coefficient, $\lambda_{s}$, as a function of Reynolds number.

The points represent experimental values, and each curve represents a constant value of $\beta$ as given in table 1 . See also figures 5 and 6.

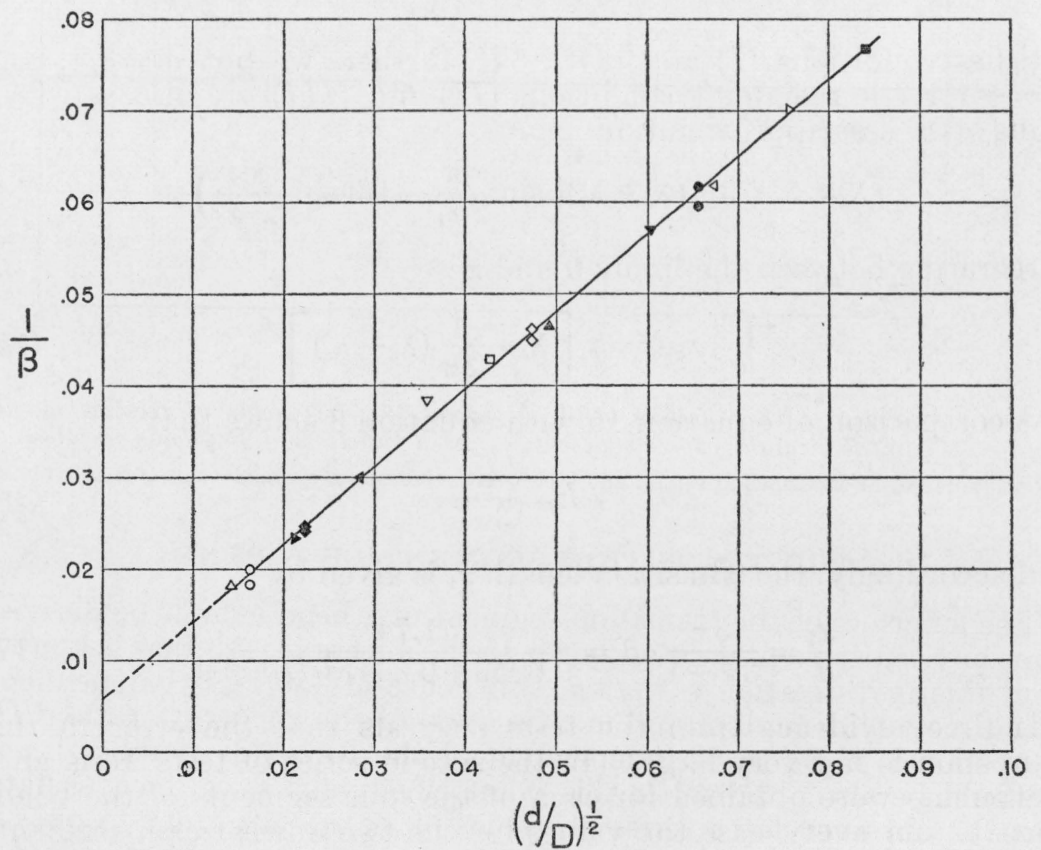

FIGURE 8.-The reciprocal of $\beta$ as a function of the square root of the curvature ratio $d / D$.

The points represent the values of $1 / \beta$ given in table 1 , and the line represents the empirical equation $1 / \beta=0.0059+0.844(d / D)^{1 / 2}$. 
Reynolds number, on the other hand, must be small enough so that the flow would remain viscous, a very viscous liquid would be required.

In the absence of experimental information, we may resort to a simple computation, first to obtain an approximate value for $x_{1}$, and second, to establish a basis for the correct expression for $x_{1}$ in case experimental results become available. It is assumed in the following computation that $x_{1}$ is independent of the Reynolds number.

Assume that $\lambda_{a}$, the resistance coefficient at any arbitrary point of the transition segment, has no discontinuities, no maxima and no minima in the interval $0<x<x_{1}$.

The end conditions are:

$$
\begin{aligned}
\lambda_{a} & =\lambda_{s} \text { at } x=0, \quad(I) \\
\lambda_{a} & =\lambda_{c} \text { at } x=x_{1}, \quad(I I) \\
\frac{d}{d x}\left(\lambda_{a}\right) & =0 \text { at } x=0, \quad(I I I), \text { and } \\
\frac{d}{d x}\left(\lambda_{a}\right) & =0 \text { at } x=x_{1} \quad(I V)
\end{aligned}
$$

A polynomial representation of $\lambda_{a}$ in circular functions satisfying the end conditions will give a first approximation of the values of $\lambda_{a}$. The expression

$$
\lambda_{a}=\lambda_{s}+\left(\lambda_{c}-\lambda_{s}\right)\left(a_{1} \sin \frac{\pi}{2} \frac{x}{x_{1}}+a_{3} \sin \frac{3 \pi}{2} \frac{x}{x_{1}}\right)
$$

satisfies conditions $(I)$ and $(I V)$. If, further, we put $a_{1}=3 / 4$, and $a_{3}=-1 / 4$, the remaining conditions $(I I)$ and $(I I I)$ are also satisfied. Thus, as a first approximation:

$$
\lambda_{a}=\lambda_{s}+3 / 4\left(\lambda_{c}-\lambda_{s}\right)\left(\sin \frac{\pi}{2} \frac{x}{x_{1}}-1 / 3 \sin \frac{3 \pi}{2} \frac{x}{x_{1}}\right) .
$$

Integrating between the limits 0 and $x_{1}$,

$$
\int_{0}^{x_{1}} \lambda_{a} d x=x_{1}\left[\lambda_{s}+\frac{4}{3 \pi}\left(\lambda_{c}-\lambda_{8}\right)\right]
$$

A comparison of equation 15 with equation 8 shows that

$$
k_{x}=\frac{4}{3 \pi},
$$

and accordingly, the transition length $x_{1}$ is given by

$$
\frac{x_{1}}{d}=\frac{3 \pi}{3 \pi-4} \cdot \beta=\frac{1.74}{0.0059+0.844(d / D)^{1 / 2}}
$$

Indirect evidence from the tests suggests that the error in this expression is not very large. In the second series of tests, resistance coefficients were obtained for each of the four segments of the bends (fig. 2). In every case the values for the two downstream segments were the same, within experimental errors, and the averages for these two segments were taken as the bend coefficient, $\lambda_{c}$. For the bend with curvature ratio $d / D=4.97 \times 10^{-4}$, the coefficient for the second segment was equal to $\lambda_{c}$, while the coefficient for the first was considerably lower. The relative transition length $x_{1} / d$, therefore, was 
something less than the relative length of the first segment, which was $x / d=88.4$. A computation from equation 17 gives in this case $x_{1} / d=66.9$.

For the bend with curvature ratio $d / D=2.62 \times 10^{-4}$, the resistance coefficient for the second segment was a very little below the bend coefficient $\lambda_{c}$. In this case the relative transition length must have been slightly greater than the relative length, $x / d=88.4$ of the first segment. The computation from equation 17 gives $x_{1} / d=88.8$.

These results indicate that, if experimental data become available, equation 14 will constitute a satisfactory starting point for a more accurate determination of $\lambda_{a}$ and $x_{1}$.

\section{RESISTANCE IN A STRAIGHT PIPE BELOW A BEND}

Let $\lambda_{z}$ designate the effective resistance coefficient in a segment of straight pipe downstream from a bend and of length $z$ measured from the downstream end of the bend. As the velocity distribution at the entrance to the tangent, at $z=0$, is that prevailing in the end portion of the bend, a certain transition length $z_{1}$ is necessary before the velocity distribution characteristic of a long straight pipe can be established. The definition of the effective coefficient, $\lambda_{z}$, is

$$
\frac{1}{\gamma} \Delta p=\lambda_{2} \frac{z}{d} \frac{U^{2}}{2 g},
$$

where $\Delta p$ is the pressure difference between the end of the bend and a point on the straight pipe at distance $z>z_{1}$ downstream. As $z$ becomes very large, $\lambda_{z}$ approaches $\lambda_{s}$ as a limit.

The coefficient $\lambda_{z}$ depends on the relative length of the segment $z / d$, on the curvature ratio $d / D$ and on the Reynolds number $R_{e}$. The analysis is analogous to that adopted above for the bend. For the effective coefficient we have the relation

$$
\lambda_{2} \cdot z=\int_{0}^{z_{1}} \lambda_{a} d z+\lambda_{s}\left(z-z_{1}\right)
$$

where $\lambda_{a}$ is the resistance coefficient at any point within the transition segment, and $z>z_{1}$. The definite integral may be written

$$
\int_{0}^{z_{1}} \lambda_{a} d z=\lambda_{s} z_{1}+k_{z}\left(\lambda_{c}-\lambda_{s}\right) z_{1}
$$

Substituting equation 20 in equation 19 , dividing by $d$, and rearranging, we have

$$
\frac{\frac{\lambda_{z}}{\lambda_{s}}-1}{\frac{\lambda_{c}}{\lambda_{s}}-1} \cdot \frac{z}{d}=k_{z} \frac{z_{1}}{d} \equiv Z,
$$

where, for convenience, we write

$$
Z \equiv k_{z} \frac{z_{1}}{d}
$$

The dimensionless quantity $Z$ may be computed from equation 21 if the resistance coefficients $\lambda_{s}, \lambda_{c}$, and $\lambda_{2}$ are known. $\lambda_{s}$ is known when the Reynolds number is given, and $\lambda_{c}$ can then be obtained from figure 4. It remains to determine $\lambda_{2}$. 
Values of $\lambda_{z}$ for a relative length of $z / d=215$ were determined with the experimental setup for the series $I$ tests at the same time that the bends were tested. The results are shown in figures 9 and 10, where the ratio $\lambda_{z} / \lambda_{s}$ is plotted as a function of the Reynolds number.

To determine $Z$, tentative curves were drawn to fit the experimental points in figures 9 and 10. About a dozen values of $\lambda_{z} / \lambda_{s}$ were read from

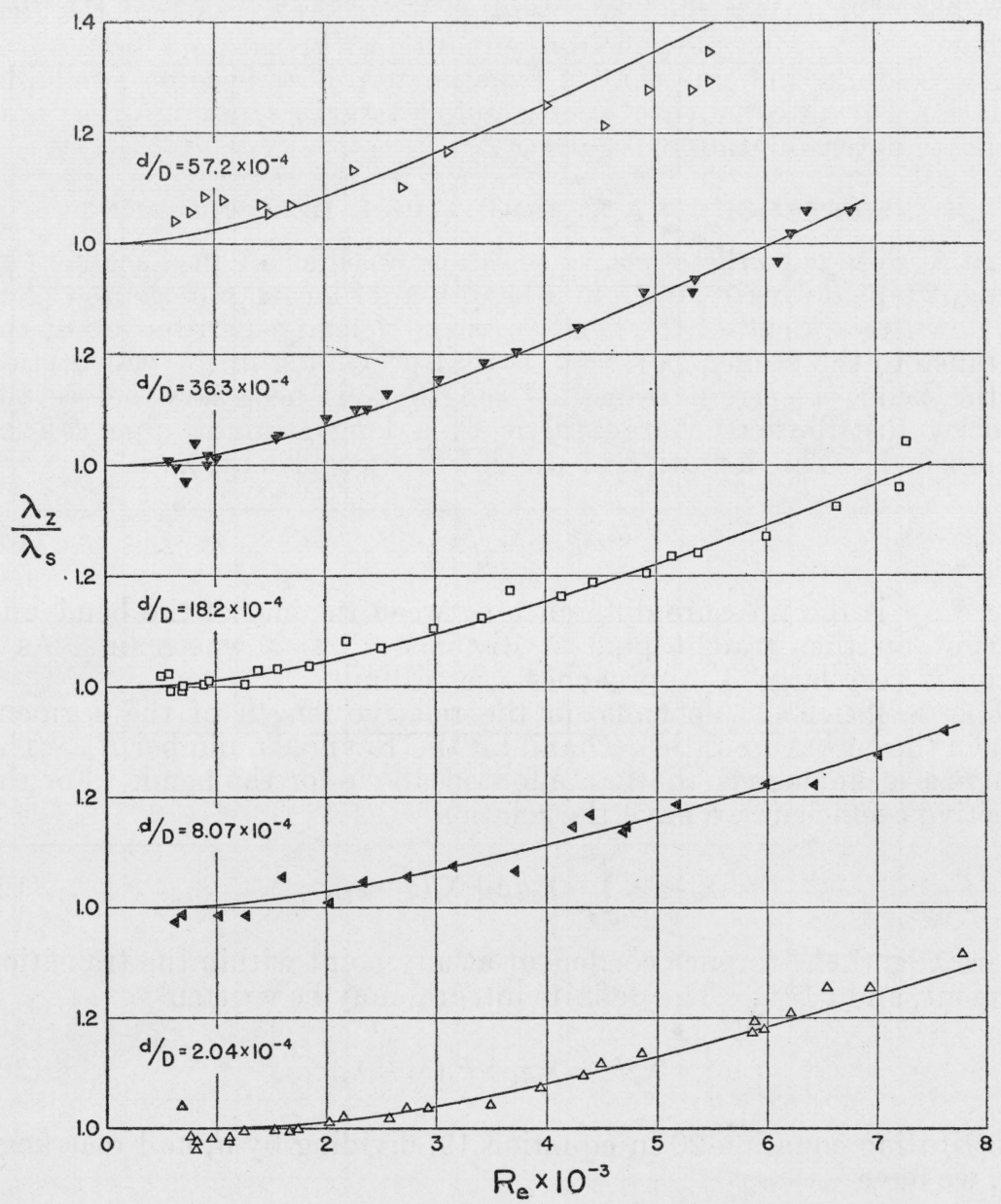

FIGURE 9.-Ratio of the effective coefficient, $\lambda_{z}$, of the downstream tangent of relative length $z / d=215$, to the straight pipe coefficient, $\lambda_{s}$, as a function of Reynolds number.

The points represent experimental values and each curve represents a constant value of $\phi$ as given in table 2. See also figure 10 .

each curve, and corresponding values of $\lambda_{c} / \lambda_{s}$ were found from the curve in figure 4. Then $Z$ was computed from equation 21. A study of the results showed that they could be expressed in the form

$$
Z=\left(\frac{\lambda_{c}}{\lambda_{s}}-1\right) \cdot \phi,
$$

where $\phi$ was a constant for each bend, that is, $\phi$ is a function of $d / D$, but not of $R_{\varepsilon}$. 
In comparing the quantity $Z$ as given by equation 23 , with the analogous quantity $\beta$ in equation 12 , it should be noticed that $\beta$ is independent of the Reynolds number and is a function of $d / D$ only, because the velocity distribution at the entrance to the bend is always parabolic, whereas at the entrance to the downstream tangent the velocity distribution depends on the flow in the bend, which is a func-

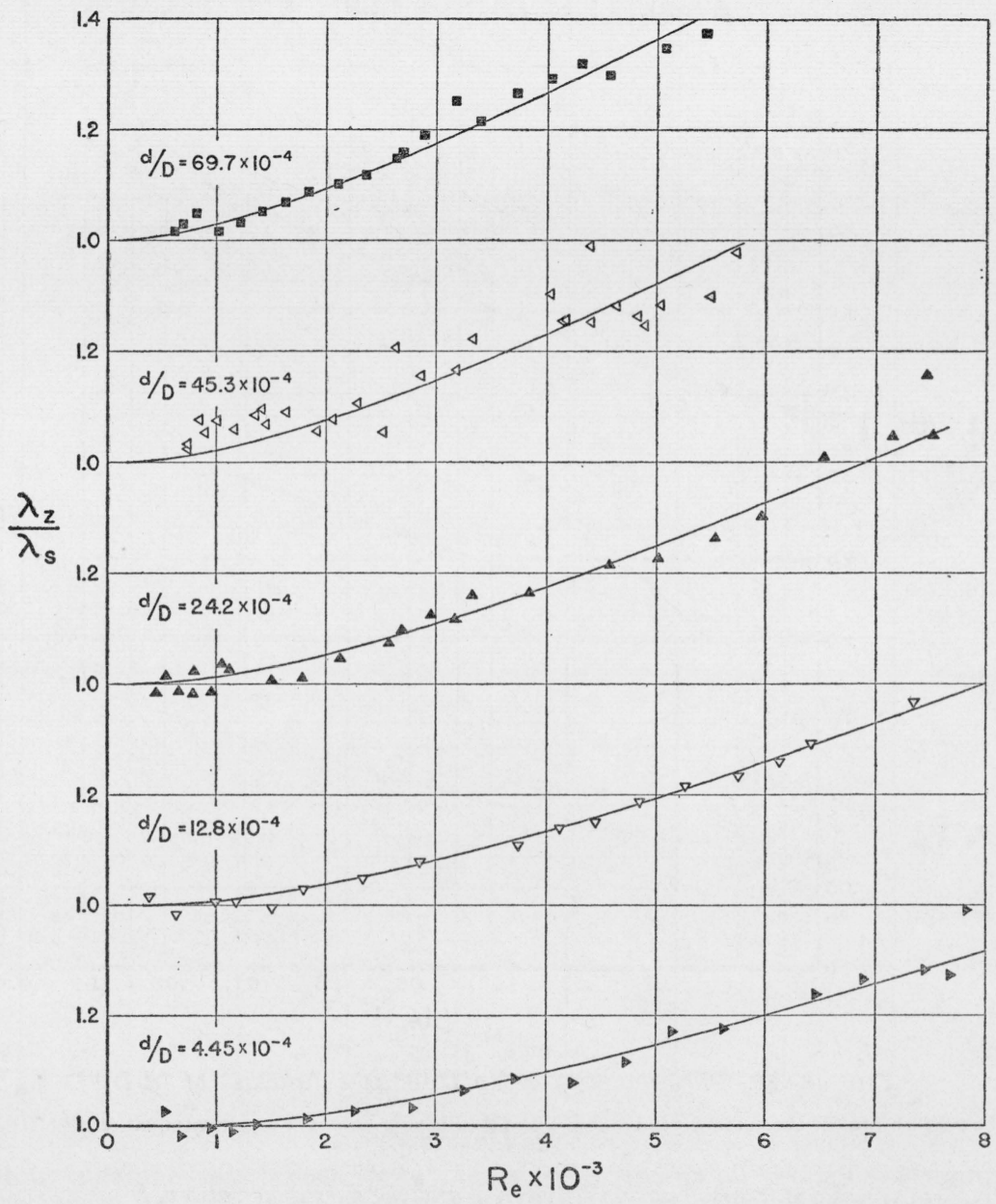

FIGURE 10.-Ratio of the effective coefficient, $\lambda_{z}$, of the downstream tangent of relative length $z / d=215$, to the straight pipe coefficient, $\lambda_{s}$, as a funciion of Reynolds number:

The points represent experimental values and each curve represents a constant value of $\phi$ as given in table 2. See also figure 9.

tion of both the Reynolds number and $d / D$. The curves drawn in figures 9 and 10 represent the final values adopted for $\phi$ as given in table 2. They appear to fit the data better than did the original tentative curves. The agreement is quite satisfactory in most cases, proving that $\phi$ is independent of Reynolds number within the errors of observation. 
An empirical relation between $\phi$ and the curvature ratio $d / D$ was found by plotting $\phi^{1 / 2}(d / D)^{1 / 2}$ as a function of $(d / D)^{1 / 2}$, as in figure 11 . The straight line representing the points is given by the equation

$$
\phi^{1 / 2}(d / D)^{1 / 2}=0.141+4.50(d / D)^{1 / 2} .
$$

Hence,

$$
\phi=\left[0.141(d / D)^{-1 / 2}+4.50\right]^{2} .
$$

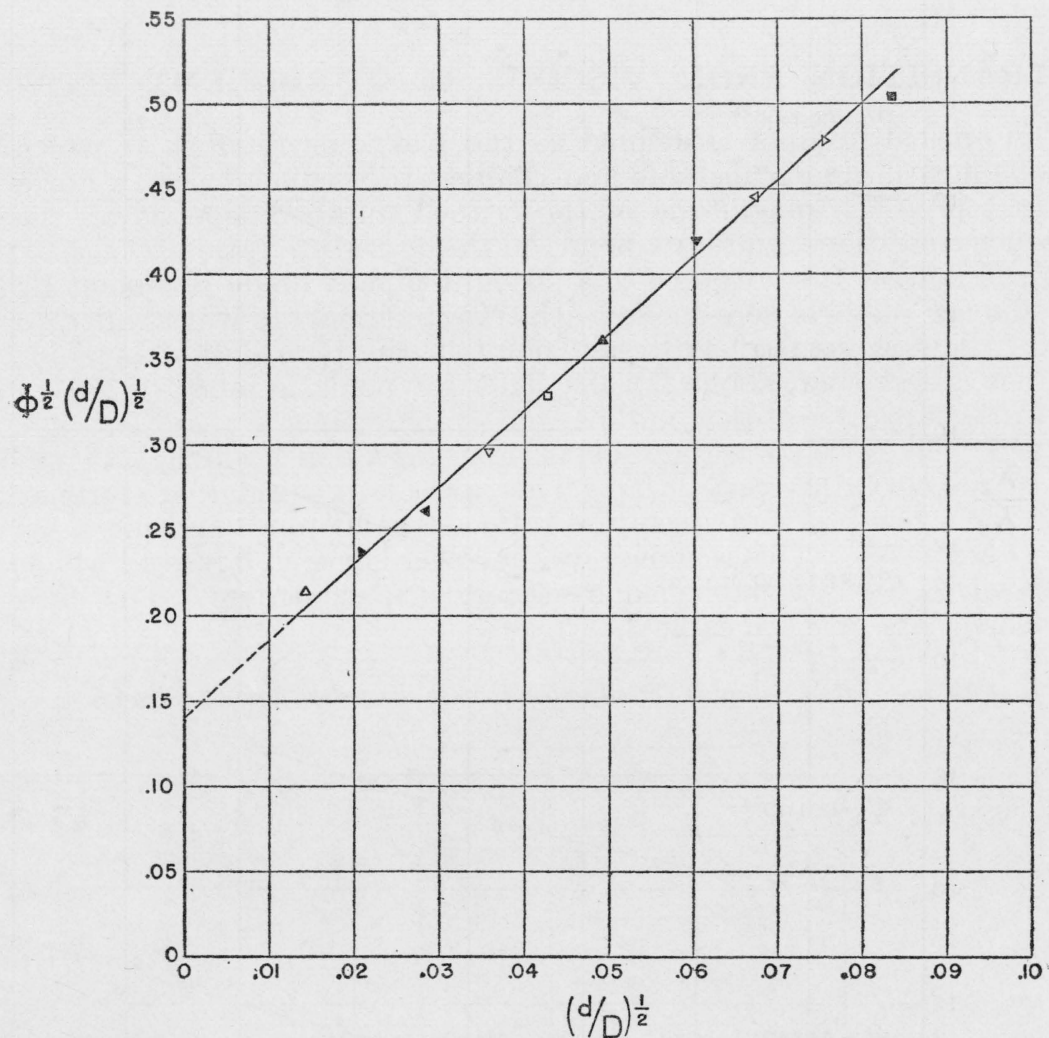

FIGURE 11.-The quantity $\phi^{1 / 2}(d / D)^{1 / 2}$ as a function of $(d / D)^{1 / 2}$.

The points represent the values given in table 2 , and the line represents the empirical equation $\phi^{1 / 2}(d / D)^{1 / 3=}$ $0.141+4.50(d / D) 1 / 2$

\begin{tabular}{|c|c|c|c|c|c|}
\hline$d$ & $z / d$ & $(d / D) \times 10^{4}$ & $(d / D)^{1 / 8} \times 10^{2}$ & $\phi \times 10^{-2}$ & $\phi^{1 / 2}(d / D)^{1 / 2}$ \\
\hline 0.950 & 215.0 & $\begin{array}{r}2.04 \\
4.45 \\
8.07 \\
12.8 \\
18.2 \\
24.2 \\
36.3 \\
45.3 \\
57.2 \\
69.7\end{array}$ & $\begin{array}{l}1.43 \\
2.12 \\
2.84 \\
3.58 \\
4.27 \\
4.92 \\
6.03 \\
6.73 \\
7.56 \\
8.35\end{array}$ & $\begin{array}{l}2.23 \\
1.25 \\
.838 \\
.685 \\
.588 \\
.535 \\
.485 \\
.434 \\
.400 \\
.365\end{array}$ & $\begin{array}{l}0.214 \\
.237 \\
.261 \\
.296 \\
.329 \\
.361 \\
.420 \\
.445 \\
.478 \\
.504\end{array}$ \\
\hline
\end{tabular}

TABLE 2.-Relation between $\phi$ and the curvature ratio $d / D$ 
Finally, combining equations 22,23 , and 25 , we have

$$
\lambda_{z}=\lambda_{s}+\frac{d}{z}\left[0.141(d / D)^{-1 / 2}+4.50\right]^{2} \frac{\left(\lambda_{f}-\lambda_{s}\right)^{2}}{\lambda_{s}},
$$

which gives the effective coefficient of resistance for a downstream tangent of length $z>z_{1}$.

A computation of $z_{1}$, similar to that of $x_{1}$ given above, would be of little interest since only one value of $z$, much larger than $z_{1}$, was used in the tests.

\section{TRANSITION FROM VISCOUS TO TURBULENT FLOW}

The critical number is defined as the Reynolds number at which viscous flow becomes unstable and changes to turbulent flow. For a straight pipe the magnitude of the critical number depends on the entrance conditions, and for a bend, on the curvature ratio $d / D$ also.

If the flow at the entrance to a straight pipe is made turbulent by introducing disturbances in any arbitrary manner, it will change to viscous flow at some downstream point in the pipe if the Reynolds number is less than about 2,200. This Reynolds number $(2,200)$ is known as the lower critical number for straight pipe.

There is likewise a lower critical number for a bend, which is a function of the curvature ratio, $d / D$. This lower critical number starts at 2,200 for a bend of zero curvature ratio (straight pipe) and increases as $d / D$ increases. This is shown by the lower curve in figure 12 which is drawn to fit data published by several experimenters. The data themselves are given in table 3.

TABLE 3.-Critical number for pipe bends with disturbed flow at entrance

\begin{tabular}{|c|c|c|}
\hline Author & $d / D \times 10^{4}$ & $\begin{array}{l}\text { Critical } \\
\text { number }\end{array}$ \\
\hline $\begin{array}{r}\text { White- } \\
\text { Do-- } \\
\text { Do- }\end{array}$ & $\begin{array}{l}\text { 4. } 89 \\
200 \\
660 .\end{array}$ & $\begin{array}{l}2,250 \\
6,000 \\
9,000\end{array}$ \\
\hline $\begin{array}{l}\text { Adler-. } \\
\text { Do } \\
\text { Do }\end{array}$ & $\begin{array}{c}50 . \\
100 \\
200 .\end{array}$ & $\begin{array}{l}3,980 \\
4,730 \\
5,620\end{array}$ \\
\hline 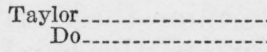 & $\begin{array}{l}310 . \\
540 .\end{array}$ & $\begin{array}{l}6,350 \\
7,100\end{array}$ \\
\hline
\end{tabular}

The critical number for a straight pipe may be increased by reducing disturbances at the entrance. In the present tests, for example, it was raised to 9,200 by the use of the special bell-mouth entrance shown in figure 3. So long, therefore, as the Reynolds number was less than 9,200 , the flow at the entrance to the bend was viscous. Under these entrance conditions, the critical numbers given in table 4 were found for the bend. These values are plotted in figure 12 (upper curve). 


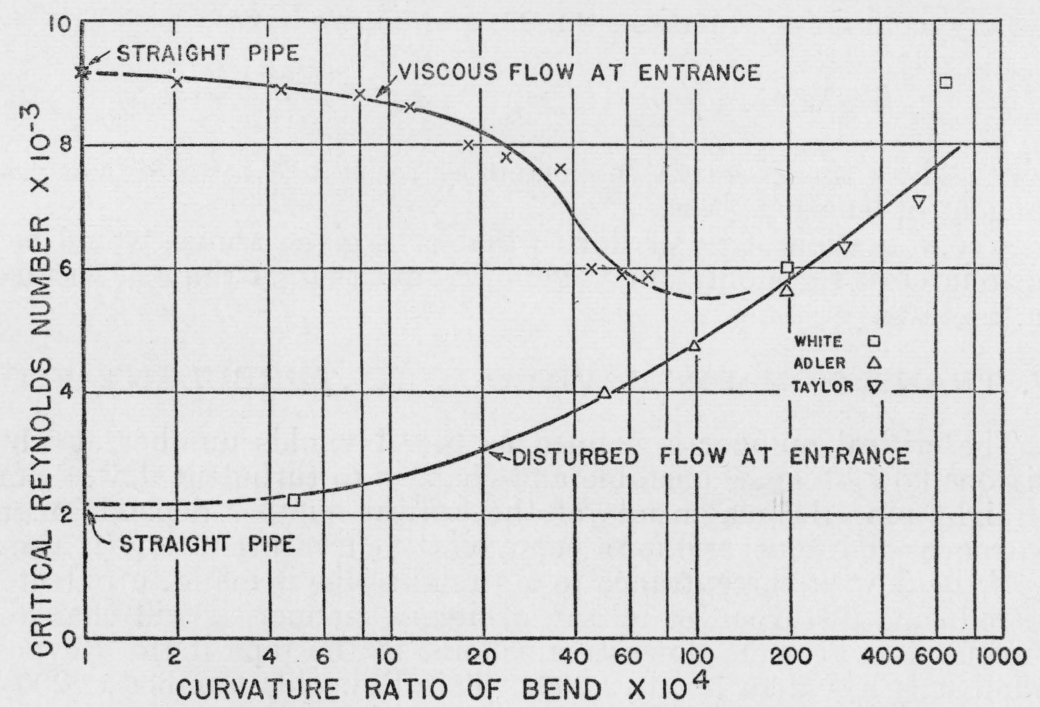

FIGURE 12.-Critical numbers for bends as function of the curvature ratio.

The crosses represent values given in table 4 , and the other points values given in table 3.

TABLE 4.-Critical number for pipe bends with laminar flow at entrance

\begin{tabular}{|c|c|c|}
\hline$(d / D) \times 10^{4}$ & $\begin{array}{c}\text { Central } \\
\text { angle } \alpha\end{array}$ & $\begin{array}{c}\text { Critical } \\
\text { number }\end{array}$ \\
\cline { 2 - 3 } & $\begin{array}{c}\text { Degrees } \\
0.00\end{array}$ & \\
2.04 & 5 & 9,200 \\
4.45 & 10 & 9,000 \\
8.07 & 20 & 8,900 \\
& 3,800 \\
12.8 & 30 & 8,600 \\
18.2 & 45 & 8,000 \\
24.2 & 60 & 7,800 \\
36.3 & 90 & 7,600 \\
45.3 & 120 & 6,000 \\
57.2 & 150 & 5,900 \\
69.7 & 180 & 5,900 \\
\hline
\end{tabular}

As it was not convenient to determine these critical numbers with any certainty by direct observations of the bend loss on the bends themselves, they were determined indirectly by observations on the straight pipe downstream. If the Reynolds number was less than 9,200 , any change from viscous to turbulent flow in this downstream pipe could be due only to turbulent flow in the bend. Hence, the downstream tangent forms a convenient detector of turbulence in the bend. The critical numbers given in table 4 were determined by inspection from the right-hand diagrams of figures 13, 14, and 15 .

It will be noticed from figure 12 that as the curvature ratio increases, the critical number decreases and approaches the values for bends with disturbed flow at entrance at a value of the curvature ratio somewhat greater than 0.01 .

In figures 13,14 , and 15 , the resistance coefficients for pipes no. 1 and no. 2 are plotted against Reynolds number in the region of change from viscous to turbulent flow. For the bends, however, there is no 

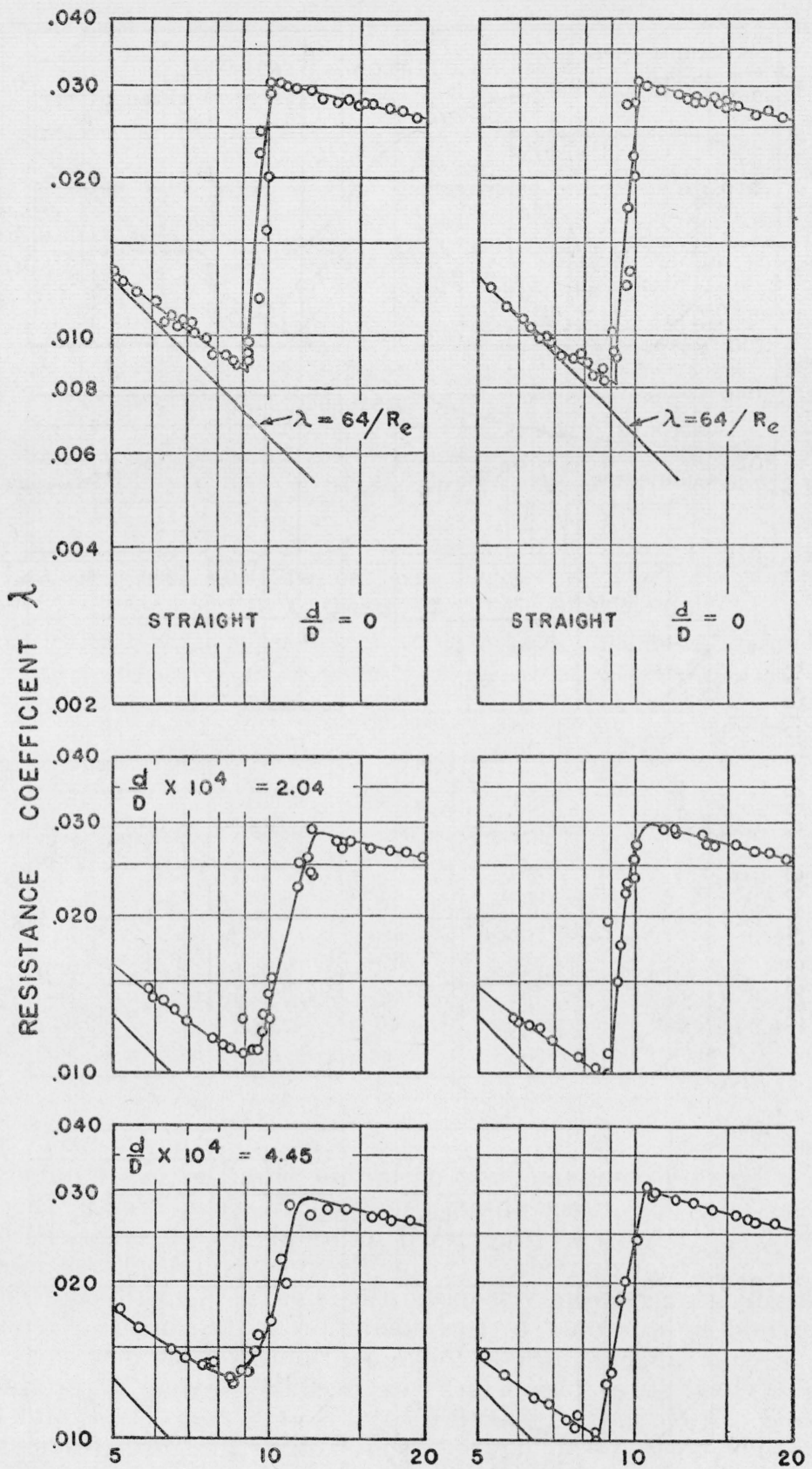

REYNOLDS

NUMBER $\times 10^{-3}$

\section{BEND}

PIPE NO.I

DOWNSTREAM TANGENT

PIPE NO. 2

FIGUR 13.-Resistance coefficients in the critical region for bends and downstream tangents as functions of Reynolds number. 

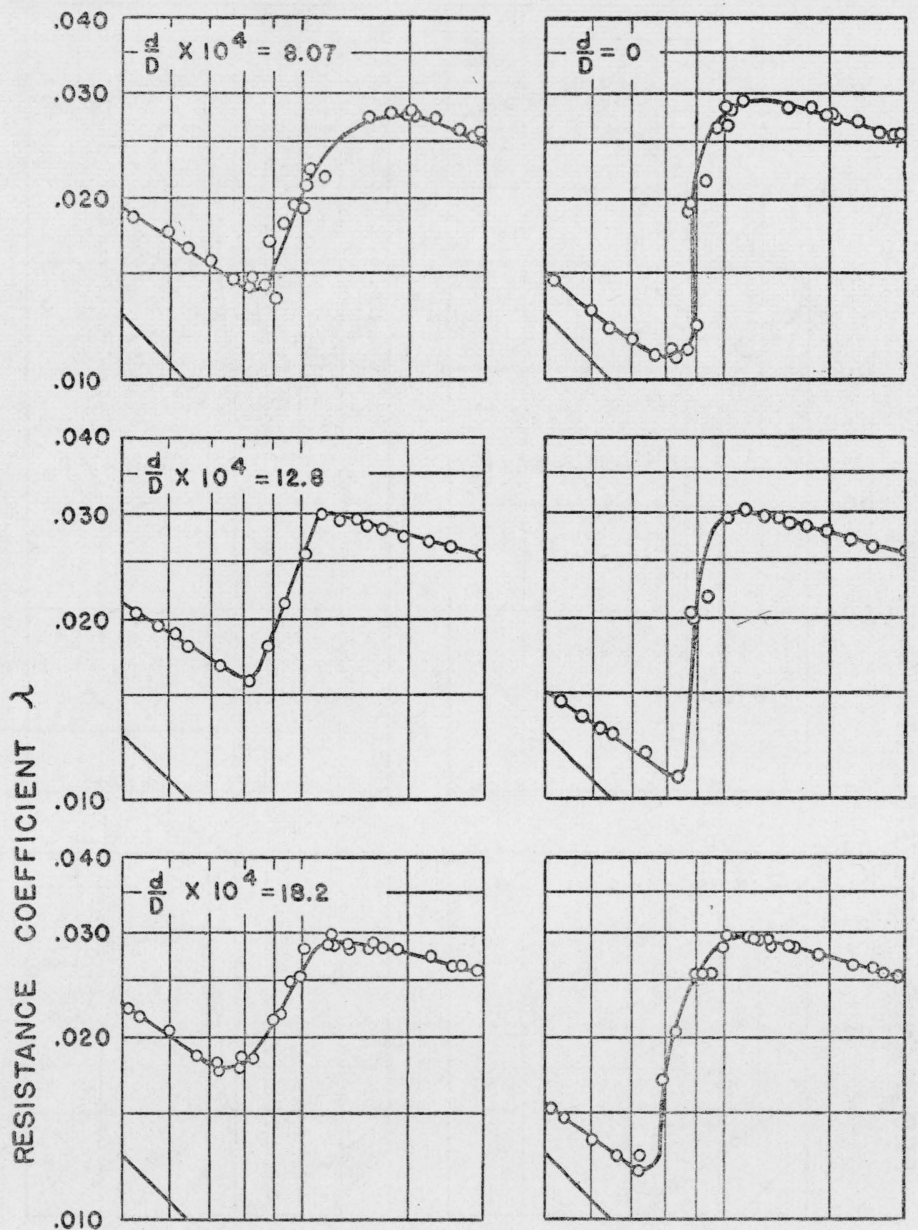

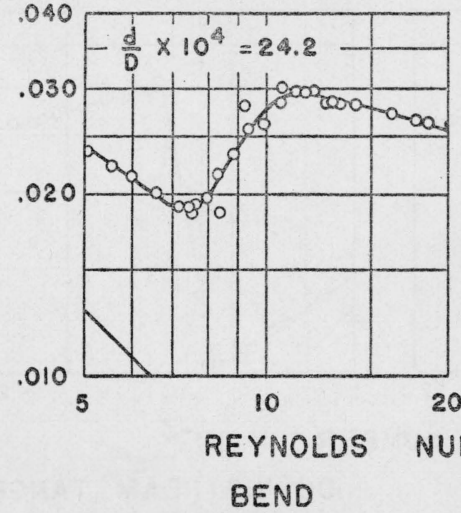

PIPE NO. 1
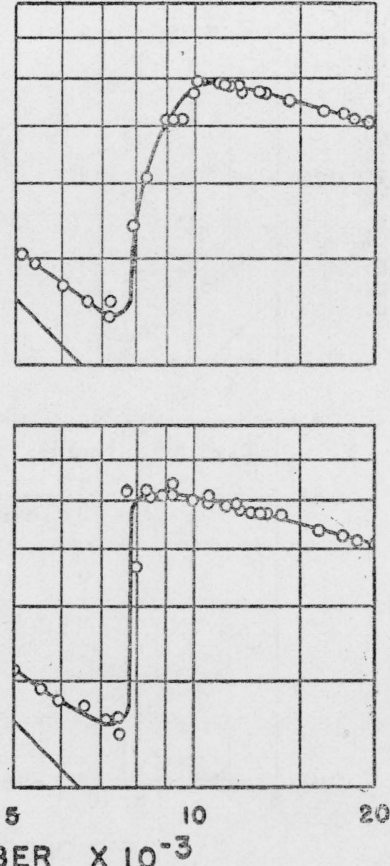

DOWNSTREAM TANGENT

PIPE NO. 2

FIGURE 14.-Resistance coefficients in the critical region for bends and downstream tangents as functions of Reynolds number. 

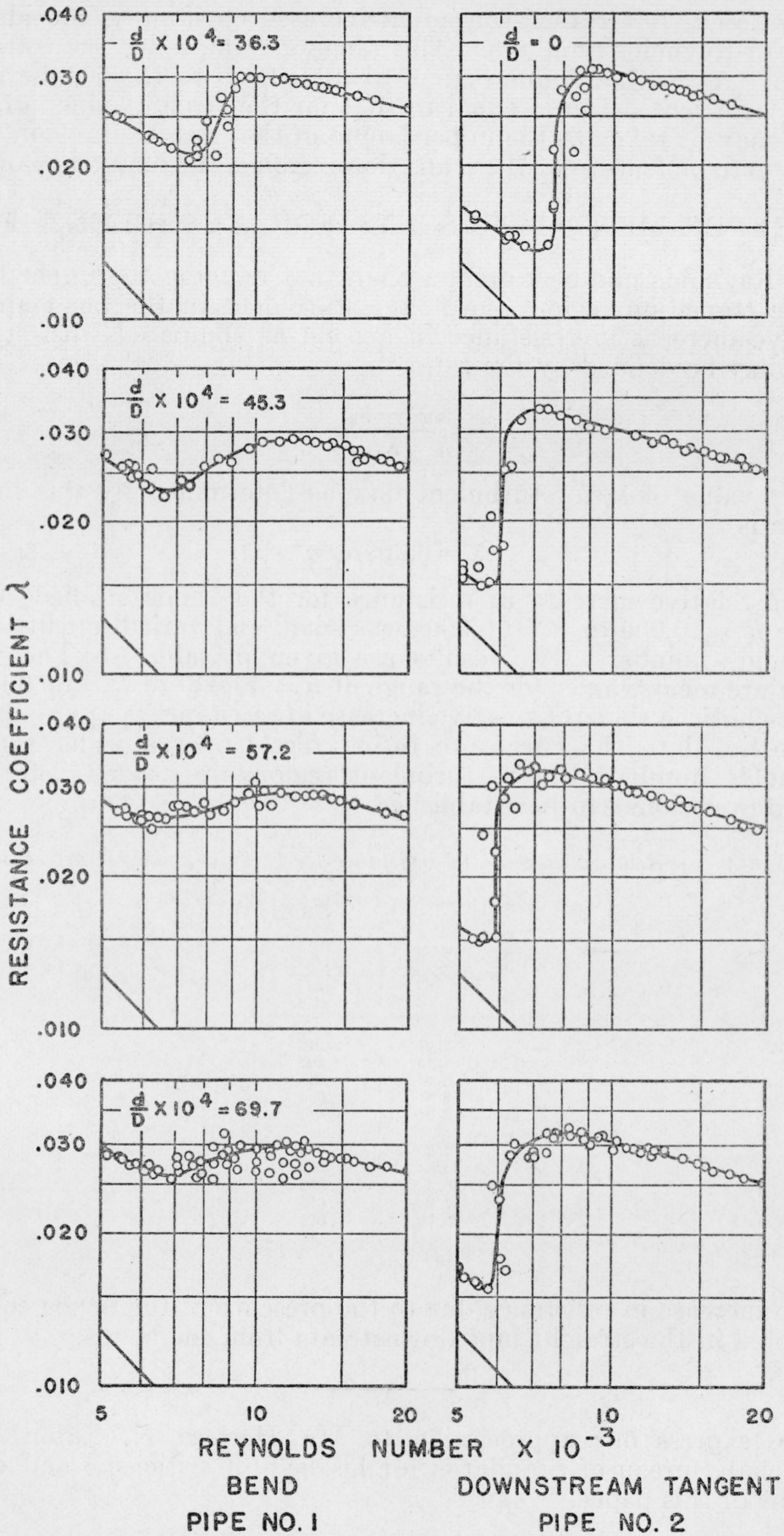

FIGURE 15.-Resistance coefficients in the critical region for bends and downstream tangents as functions of Reynolds number. 
sharp break, but rather a gradual increase covering a considerable range of Reynolds numbers. This range may be called the transition region. At Reynolds numbers of about 10,000 to 13,000 , the resistance coefficient becomes equal to that for the straight pipe, and this point may be taken as the upper bound of the transition region. The characteristic feature of the transition region is the instability of flow.

\section{EXPERIMENTAL RESULTS FOR TURBULENT FLOW}

At Reynolds numbers greater than that defining the upper bound of the transition region, the flow is turbulent in the bend and the relative increase in resistance in a bend as compared with straight pipe may be defined by the ratio

$$
\frac{\lambda_{c}-\lambda_{s}}{\lambda_{s}}
$$

The value of $\lambda_{s}$ for turbulent flow as determined by this investigation is

$$
\lambda_{s}=0.309 R_{e}^{-1 / 4} \text {. }
$$

The relative increase in resistance for the bends studied (in the range $R_{e}=40,000$ to $R_{e}=60,000$ ) was small and varied but little with Reynolds number. The results are given in table 5. The values given are mean values for the range of $R_{e}=40,000$ to $R_{e}=60,000$. It will be noticed that the relative increase in resistance is approximately proportional to the curvature ratio. Tests over a wider range of Reynolds numbers in the turbulent region are needed before any definite relations can be established.

TABLE 5.-Relative increase in resistance for turbulent flow in pipe bends

[Mean values for the range $R_{\mathrm{s}}=40,000$ to $R_{\mathrm{o}}=60,000$ ]

\begin{tabular}{|c|c|}
\hline$d / D \times 10^{4}$ & $\frac{\lambda_{c}-\lambda_{s}}{\lambda_{s}}$ \\
\hline 2.04 & 0.010 \\
4.45 & .006 \\
8.07 & .011 \\
12.8 & .010 \\
18.2 & .017 \\
24.2 & .028 \\
36.3 & .042 \\
45.3 & .058 \\
57.2 & .057 \\
69.7 & .073 \\
\hline
\end{tabular}

No increase in resistance due to the presence of the bends could be detected in the straight pipe downstream from the bends.

We express our appreciation to Mr. Herbert N. Eaton of the National Bureau of Standards for his helpful criticisms and careful review of this paper.

WASHington, October 19, 1936. 